\title{
Conhecimentos, Valores e Práticas Sociais referentes à Sexualidade: implicações na formação inicial de pedagogas
}

\author{
Knowledge, Values, and Social Practices related to sexuality: \\ implications in the initial training of educators
}

\author{
Giséli Duarte Bastos ${ }^{1}$, Rosemar de Fátima Vestena ${ }^{2}$; Lenira Maria Nunes Sepel ${ }^{3}$ \\ 1 Doutora em Educação em Ciências, Universidade Federal de Santa Maria, Santa Maria, Rio Grande do Sul, Brasil - \\ giseli.bastos@ufsm.br,/ORCID \\ 2 Doutora em Educação em Ciências, Universidade Franciscana, Santa Maria, Rio Grande do Sul, Brasil - \\ rosemarvestena@gmail.com,/ORCID \\ 3 Doutora em Educação em Ciências, Universidade Federal de Santa Maria, Santa Maria, Rio Grande do Sul, Brasil - \\ lenirasepel@gmail.com,/ORCID
}

\section{Recebido em Março/2018. Publicado em Abril/2020}

Palavras-chave:

Pedagogia. Formação

inicial. Sexualidade.

Valores. Práticas sociais.

\section{Keywords:}

Pedagogy. Initial

training. Sexuality.

Values. Social practices.

ISSN 1983-7011
RESUMO: O curso de Pedagogia é responsável por formar profissionais que, entre outras atuações possíveis, desempenharão papéis didáticos, pedagógicos e psicopedagógicos em diversos espaços educacionais. Abordar, no contexto escolar, sexualidade, com suas derivações biológicas e sociais, representa um desafio importante para esses educadores, tendo em vista as complexas relações e intervenções exigidas a partir da temática, as quais são relevantes para a formação integral dos indivíduos desde a infância. Assim, investigamos um grupo de treze pedagogas em formação inicial de uma instituição privada, localizada na região central do RS, Brasil, quanto às manifestações de conhecimentos $(\mathrm{K})$, valores $(\mathrm{V}) \mathrm{e}$ práticas sociais (P) (CLÉMENT, 2006), em relação à temática da sexualidade, materializadas após uma disciplina voltada ao assunto. Entre os resultados, analisados à luz da análise de conteúdo (BARDIN, 2011), destacamos uma incipiente utilização dos $\mathrm{K}$ por parte das estudantes quando questionadas sobre como agiriam no ambiente escolar, embasando suas ações, principalmente, em seus $\mathrm{V}$. Ainda, encontramos $\mathrm{V}$ que suscitam certo grau de estigmatização das pessoas portadoras de HIV, bem como algumas manifestações que estereotipam gênero, ao procurarem aconselhar que as meninas protejam-se contra gravidez e infecções sexualmente transmissíveis, abstendo os meninos do compartilhamento dessa responsabilidade. A partir dos resultados, consideramos ser essencial desenvolver estratégias na formação de pedagogos para a efetivação de uma aprendizagem conceitual que possa melhor balizar as práticas sociais desses profissionais, além de promover reflexões acerca dos valores que sustentam suas ações em relação à sexualidade.

ABSTRACT: The Pedagogy course is responsible for training professionals who, among other potential practices, carry out didactic, pedagogical, and psychopedagogical roles in several educational spaces. In the school context, addressing sexuality, with their biological and social derivations, represents a major challenge for those educators, considering the complex relationships and required interventions of the topic, which are relevant to the integral education of the individuals from early childhood. Thus, we investigated a group of thirteen educators in their initial training in a private institution, located in the central region of Rio Grande do Sul, Brazil, analyzing the demonstrations of knowledge $(\mathrm{K})$, values $(\mathrm{V})$, and social practices $(\mathrm{P})$ (CLEMENT, 2006), in relation to the topic of sexuality, materialized after a course dedicated to the subject. The results were analyzed in the light of the content analysis (BARDIN, 2011). We highlight an incipient use of $\mathrm{K}$ by the students when 
questioned about how they would react in the school environment, basing their actions especially on their $\mathrm{V}$. We also find $\mathrm{Vs}$ that raise a certain degree of stigmatization of people with HIV, as well as some demonstrations of gender stereotyping, when they attempt to advise girls to protect themselves against pregnancy and sexually transmitted diseases by eschewing the responsibility-sharing of the boys. Considering these results, we believe it is essential to develop strategies when training educators to implement a conceptual learning that might best mark the social practices of these professionals, in addition to fostering reflections on the values that support their actions in relation to sexuality.

\section{INTRODUÇÃO}

A educação sexual ou orientação sexual ${ }^{1}$ é um processo de aprendizagem e formação de atitudes e crenças sobre sexualidade $^{2}$, abrangendo dimensões biológicas e sociais/emocionais, o qual pode ser realizado em âmbito escolar, além de outros meios, como a família, por exemplo. Acredita-se que, por meio da educação sexual, crianças e jovens, principalmente, podem desenvolver habilidades para realizar escolhas conscientes e baseadas em informações mais próximas do conhecimento científico, sentindo-se confiantes acerca de suas ações a partir dessas escolhas (SABAH et al., 2010). Proteção e informação preventiva acerca de abusos e exploração sexual, gravidez, infecções sexualmente transmissíveis (IST), além de questões de gênero, orientação sexual e preconceitos que derivam desses tópicos são algumas abordagens possíveis na escola.

Nos anos 2000, a difusão das orientações propostas nos Parâmetros Curriculares Nacionais (BRASIL, 1997), incluiu publicações sobre os temas transversais que, por corresponderem atemáticas sociais relevantes para abordagem na Educação Básica, deveriam estar presentes nos currículos das escolas. A transversalidade ao longo da escolaridade foi proposta considerando-se a complexidade e a necessidade de integração desses temas com todas as áreas de conhecimento.

Um dos temas transversais é a educação sexual, Felipe e Guizo (2004), no entanto, apontam lacunas na apresentação dessa temática, tanto nas escolas de ensino médio (modalidade normal), quanto nos cursos de formação docente em nível universitário. Para esses autores, os currículos ainda não contemplam de forma abrangente a temática, nem apresentam de modo efetivo oportunidades de discussão acerca das questões relacionadas a sexo e sexualidade.

\footnotetext{
1Neste trabalho utilizaremos o termo educação sexual de acordo com Cardoso (2008), uma vez que, para o autor, "orientação sexual" pode adquirir sentido ambíguo, pois também pode designar a atração sexual ou ligação afetiva que se sente por outra pessoa, de onde derivam os termos heterossexual, homossexual, bissexual, assexual.

2Sexualidade deve ser entendida neste trabalho como expressão que abrange dimensões biológicas - sexo-, portanto anatômicas e fisiológicas, e também sociais/pessoais, como as questões de gênero, orientação sexual, entre outras.
} 
Muitos pesquisadores, a exemplo de Furlani (2009), enfatizam a relevância de conhecimentos inerentes à sexualidade para a formação integral do indivíduo desde a infância. Para a autora, a educação sexual deve começar nessa fase e, portanto, fazer parte do currículo escolar. As temáticas discutidas na educação sexual são conhecimentos imprescindíveis à formação integral da criança e do/a jovem. A sexualidade se manifesta na infância, na adolescência, na vida adulta e na terceira idade. Esperar para abordar a sexualidade apenas na adolescência reflete uma visão pedagógica limitada, baseada na crença de que a "iniciação sexual" só é possível a partir da capacidade reprodutiva (puberdade) (FURLANI, 2009).

Para abordagem efetiva do tema transversal educação sexual no Ensino Fundamental torna-se necessário que a formação de pedagogos inclua discussões sobre o assunto e uma maior sistematização de informações, pois, de acordo com a legislação brasileira, o exercício docente na educação infantil, e nos cinco primeiros anos do Ensino Fundamental, demanda curso superior de Licenciatura Plena em Pedagogia, admitindo-se ainda, como formação mínima, a modalidade Normal (BRASIL, 1996).

A pesquisa relatada neste artigo foi desenvolvida dentro do contexto de uma disciplina oferecida para formação docente inicial em Pedagogia. Os objetivos da disciplina foram: integrar aspectos biológicos e sociais acerca da sexualidade, fornecer embasamento teórico que permita a abordagem da temática educação sexual em diferentes contextos educativos e discutir as contextualizações possíveis, utilizando-se situações passíveis de ocorrerem no cotidiano escolar.

A pesquisa em ensino adquire uma dimensão mais complexa quando os sujeitos são docentes em formação (inicial ou continuada), pois as questões associadas à investigação ultrapassam as aprendizagens conceituais dos envolvidos ou de como eles poderão agir em suas práticas sociais no dia-a-dia. Abre-se a possibilidade de investigar também como eles irão colocar em 'ação de sala de aula' esses conhecimentos, quais decisões serão moduladas por seus valores e suas percepções de contextos educativos e sociais. A questão que deu origem a esse trabalho está relacionada ao processo de transposição didática necessário para incluir as informações sobre educação sexual na Educação Básica e pode ser expressa do seguinte modo: que conhecimentos, valores e práticas sociais podem ser evidenciados quando o pedagogo em formação realiza uma nova transposição didática acerca de temáticas relacionadas ao sexo e à sexualidade, depois de ter sido exposto às sistematizadas apresentadas em uma disciplina de graduação?

Com o objetivo de identificar manifestações de conhecimentos, valores e possíveis práticas sociais, analisamos os produtos criados por estudantes de Pedagogia, durante uma 
Ensino, Saúde e Ambiente - V13 (1), pp. 57-83, Abr. 2020

disciplina denominada Educação e Sexualidade. Buscamos compreender como a presença de conceitos científicos, aplicados às questões inerentes a sexo e sexualidade, inter-relacionamse com valores e podem expressar-se na atuação profissional. Os resultados encontrados também foram analisados para elucidar lacunas no contexto de formação inicial dos sujeitos que participaram da pesquisa e para conduzir à reformulação de nossas próprias práticas.

Tendo em vista amplitude e a diversidade de conceitos e informações que derivam das investigações sobre sexualidade e transposição didática, torna-se necessário a apresentação mínima dos referenciais teóricos que amparam esta pesquisa. Os segmentos Transposição Didática na Prática Docente e Sexualidade e suas implicações contextuais, que encerram a introdução, têm por finalidade situar o leitor em relação às ideias norteadoras da pesquisa, sem a pretensão de constituir acervos de revisão sobre esses temas.

Times New Roman 12, negrito, maiúscula, alinhado à esq., 6pt antes, 0pt depois

\section{TRANSPOSIÇÃO DIDÁTICA NA PRÁTICA DOCENTE}

Os processos ensinar e aprender são objetos das mais diversas análises e podem ser descritos de modos variados. Para Charlot (2000) aprender é uma relação entre duas atividades: a atividade humana que produziu aquilo que se deve aprender (saber ou conhecimento científico) e a atividade na qual o sujeito que aprende se engaja - sendo a mediação entre ambas assegurada pela atividade daquele que ensina. O saber científico para se transformar em noções suscetíveis de aprendizagem, passa pela didatização. Tal processo nos encaminha à noção de Transposição Didática (TD), que todo professor, de alguma forma, realiza no esforço de possibilitar ao aluno a apropriação e a reconstrução de determinado saber.

O conceito de transposição didática (TD) foi proposto inicialmente pelo sociólogo Verret, em 1975, e, mais tarde, desenvolvido por Yves Chevallard, em 1985, e aprimorado anos após (MENDOZA, 2005). Chevallard analisou, no domínio da Matemática, a passagem do "saber científico" (saber sábio), de referência, para o "saber a ensinar" e deste para o "saber ensinado"; posteriormente este modelo foi aplicado a outras áreas disciplinares, como as Ciências (ASTOLFI, DEVELAY, 2001). Para Chevallard (1991), o saber não chega à sala de aula tal como foi produzido no contexto científico porque os objetivos da comunidade científica e da escola são diferentes.

A partir do "saber sábio", construído no interior da comunidade científica, passamos ao "saber a ensinar" o qual, por ação de uma diversidade de agentes - a chamada "noosfera"composta por políticos, acadêmicos, membros do sistema educacional, seleciona os 
Ensino, Saúde e Ambiente - V13 (1), pp. 57-83, Abr. 2020

conhecimentos a serem transpostos e os reconstrói para torná-los "ensináveis", correspondendo à Transposição Didática Externa (SIQUEIRA; PIETROCOLA, 2006). Esse nível de saber, materializado na produção de livros didáticos, manuais de ensino para a formação universitária e programas escolares sofre descontextualizações por meio de um processo denominado por Chevallard (1991) de despersonificação. Nesse sentido, o saber passa a ter uma configuração dogmática, cumulativa e, de certa forma, linearizada. Ainda, ao ser reconstruído em um novo contexto epistemológico, diferente do qual foi produzido enquanto saber sábio, o saber a ensinar passa por uma dessincretização (CHEVALLARD, 1991).

Já a Transposição Didática Interna preocupa-se com a maneira como os conteúdos são transpostos em contextos de aprendizagem formais e não formais, compondo o fenômeno da didatização (SIQUEIRA; PIETROCOLA, 2006). Assim, na sala de aula, a partir das ações do professor, principal personagem dessa etapa, o saber aparece na forma de "saber ensinado", o qual, na interação com os alunos, será transformado em "saber aprendido" (MARANDINO et al., 2016).

Conforme Winslow (2011), circulou no meio acadêmico a ideia errônea e superficial de que a TD se reduz ao mero transporte de conhecimento de diferentes fontes aos estudantes. Para o autor, no entanto, a TD volta-se para revelar e analisar as mudanças profundas pelas quais conhecimentos e práticas passam ao ser transpostos de uma instituição para outra. Assim, a TD não precisa, necessariamente, representar distorções e vulgarizações do saber, uma vez que o saber sempre exige uma atividade de produção original. A cada novo período letivo, por exemplo, o saber a ser ensinado é parcialmente recriado pelo professor, em um desafio inédito partilhado com os alunos.

A esse respeito, Araujo et al. (2009, p. 3) apresentam que.

A priori poderíamos supor que os conhecimentos científicos são universais, tendo como referência as mesmas publicações e, consequentemente, seriam os mesmos em todos os programas de ensino e nos manuais escolares, bem como, seriam também idênticas, as concepções dos professores sobre as mesmas matérias de ensino.

Destacam, no entanto, que a universalidade do conhecimento é relativa para as chamadas "questões vivas", as quais mesclam tanto debates científicos como sociais. Esses autores usam como tema de pesquisa o ensino da evolução biológica e salientam a diversidade de compreensões e TD, mesmo que as referências (publicações, livros didáticos, manuais, programas de ensino) sejam as mesmas.

Nesse contexto, considerando o tema sexualidade como um bom representante do grupo de "questões vivas", as possibilidades de TD são diversas e os caminhos possíveis de serem utilizados pelos docentes não serão lineares. Clément (2006), ao explorar a 
complexidade e a não linearidade da TD, propõe um modelo para organizar os principais elementos que fazem parte do processo. O modelo é representado pelas letras KVP correspondentes a três polos que interagem entre si: $K$ ( $K$ de conhecimento em inglês knowledge), V (valores) e P (práticas sociais). A interação entre os polos dos diversos agentes que compõem o sistema educativo sejam eles cientistas, didatas, professores, alunos, ou ainda dos programas ou manuais escolares, representa as concepções desses sujeitos e agentes. Clément (2006) destaca ainda que a influência desses polos é percebida tanto na transposição didática externa (programas de ensino e livros didáticos, por exemplo), quanto na interna (práticas pedagógicas dos docentes que se efetivam nas salas de aula, por exemplo).

De acordo com o autor, o polo K refere-se à informação proveniente da comunidade científica e também aos conhecimentos que cada um tem, sejam eles próximos ou afastados do conhecimento científico. O polo $\mathrm{P}$ representa as práticas sociais, como as práticas de ensino dos professores, incluindo as suas concepções relacionadas com as práticas sociais atuais e futuras dos estudantes a que se dirigem, as práticas profissionais dos futuros estudantes, além das práticas de cidadania atuais e futuras. O polo $\mathrm{V}$ configura os valores, os quais são assumidos num sentido lato do termo, incluindo opiniões, crenças e ideologias (CLÉMENT, 2006).

Assim, passamos a nos remeter à sexualidade a qual, como citado anteriormente, trata-se de uma "questão viva" socialmente, suscitando as mais diversas manifestações. Por esse motivo, no contexto da formação de professores, torna-se oportuna a utilização do modelo KVP para analisar a evolução da aprendizagem a partir das suas interações com os valores e as práticas sociais dos futuros professores sobre a temática.

\section{A SEXUALIDADE E SUAS IMPLICAÇÕES CONTEXTUAIS}

Para Louro (2014) há dois pontos cruciais para o entendimento da sexualidade: o primeiro deles remete-se à compreensão de que a sexualidade não é apenas uma questão pessoal, mas é social e política; o segundo, ao fato de que a sexualidade é construída, ao longo de toda a vida, de muitos modos, por todos os sujeitos. Para a autora, a sexualidade envolve linguagens, fantasias, representações, símbolos e convenções; processos esses culturais e plurais ao longo da história.

Para exemplificar a complexidade que envolve o tema, em nível de Transposição Didática Externa, um excerto do Plano Nacional da Educação (PNE), específico sobre gênero e orientação sexual ("superação das desigualdades educacionais, com ênfase na promoção de igualdade racial, regional, de gênero e de orientação sexual") foi substituído por uma redação 
ampla e inespecífica ("erradicação de todas as formas de discriminação") (BRASIL, 2011, p.1), podendo ser entendida como uma forma de omissão, alicerçada em valores. Também são exemplos de situações envolvendo valores em nível de Transposição Didática Externa os movimentos que conquistam notoriedade atualmente, especialmente nas mídias sociais, incentivando manifestações contra o que considerariam como "ideologia de gênero" nas escolas, exigindo o silenciamento dos professores quanto ao tema (REIS; EGGERT, 2017).

A normatização da sexualidade nas políticas públicas é para Foucault (1988) um "dispositivo histórico" que sugere a direção e a abrangência do olhar sobre a sexualidade:

Um conjunto decididamente heterogêneo que engloba discursos, instituições, organizações arquitetônicas, decisões regulamentares, leis, medidas administrativas, enunciados científicos, proposições filosóficas, morais, filantrópicas [...] o dito e o não dito são elementos do dispositivo. O dispositivo é a rede que se estabelece entre esses elementos (FOUCAULT, 1995, p.244).

Se o tema sexualidade apresenta contrariedades na Transposição Didática Externa, elas não são menores na etapa de Transposição Didática Interna. A dificuldade materializa-se no incômodo que sentem muitos professores quando são questionados sobre assuntos referentes à sexualidade (ARRUDA, 2008). Para o autor, os professores algumas vezes respondem, outras se esquivam ou ainda pedem auxílio para outros profissionais para falar do "problema". As motivações e as causas para tais desconfortos têm origens diversas: motivos religiosos, psicológicos, políticos, insuficiência de conhecimentos, entre outros. Para Carvalho, Andrade e Menezes (2009) uma das causas da resistência à adoção de propostas educacionais que abordem a sexualidade segundo princípios do respeito à diversidade e da equidade é, justamente, o conflito entre os valores políticos e éticos inerentes a essas propostas e muitos dos valores religiosos e morais, profundamente arraigados.

O educador, ao silenciar-se ou ao ser silenciado deixa de suscitar discussões importantes sobre igualdade e desconstrução de preconceitos. Nesse contexto, Louro (2000) discorre que na atribuição do que é certo ou errado, normal ou patológico, aceitável ou inadmissível está implícito um amplo exercício de poder que, socialmente, discrimina, separa e classifica. E, como não poderia deixar de ser, a realidade social discriminatória também se reflete na escola (OLIVEIRA; FARIA, 2011).

A inclusão da temática sexualidade nos currículos escolares tem como alicerces o surgimento da epidemia do HIV/AIDS e o reconhecimento da gravidez na adolescência como um "problema de saúde física e social" (CÉSAR, 2009). O fortalecimento do paradigma "informação como arma" consolidou as abordagens e discursos sobre o tema sexualidade em torno da ideia de prevenção contra infecções sexualmente transmitidas e gestações consideradas precoces (OLIVEIRA; FARIA, 2011; CÉSAR, 2009; DINIS; ASINELLI-LUZ, 
2007; ALTMANN, 2003).Nesse cenário, coube aos professores de Ciências Biológicas responderem pela educação sexual na escola, tendo como recurso prioritário os livros didáticos. O efeito da destinação desse tema transversal, que deveria ser transversal, para as aulas de Ciências e Biologia foi o reforço de um modelo biomédico, com caráter disciplinar e normativo; em detrimento da abordagem de questões sociais, culturais, históricas e emocionais relacionadas com a sexualidade (ALTMANN, 2007; DE TILIO; MARTINS; MORELLI, 2014). A necessidade de ampliar a apresentação e discussão sobre sexualidade na escola se reflete nos resultados de várias pesquisas apontando que os professores/educadores são favoráveis à inclusão da Educação Sexual nos cursos de formação inicial e reconhecem a importância de ações e intervenções educativas que lhes possibilite reverem seus conceitos e preconceitos (SILVA; MEGID NETO, 2006).

As críticas em relação a uma visão reducionista e simplificadora que privilegia um enfoque biologicista, com ênfase no discurso de prevenção às infecções, são válidas, mas, se forem considerados os dados da Unaids Brasil (2016), há outro tipo de ponderação precisando ser feita. Em 2016 foram registradas 1,8 milhão de novas infecções por HIV, sendo 160 mil em crianças abaixo de 15 anos e nos anos anteriores houve aumento de $32 \%$ nos casos de sífilis. Se a abordagem da temática sexualidade tem tido ênfase biológico-preventiva, pode-se concluir que as estratégias para promover saúde no exercício da sexualidade precisam ser revistas, mas não abandonadas.

A falta de conhecimentos básicos sobre anatomia, fisiologia, métodos contraceptivos entre os adolescentes aparece como resultados de várias pesquisas (GOMES et al., 2002; JEOLÁS; FERRARI, 2003; CARVACHO; SILVA; MELLO, 2008). Carvacho, Silva e Mello (2008) associam a falta de conhecimentos sobre o próprio corpo com os problemas enfrentados pelos jovens no exercício da sexualidade, resultando na gravidez não planejada e no uso de medida extremas, como o aborto, com consequências físicas e psicológicas devastadoras para os envolvidos.

\section{METODOLOGIA}

A presente pesquisa, de natureza empírica e qualitativa, foi desenvolvida durante uma disciplina optativa ${ }^{3}$ ofertada ao Curso de Pedagogia Noturno, de uma Instituição privada de Ensino Superior, localizada na região central do Rio Grande do Sul (RS) - Brasil, no

\footnotetext{
3As disciplinas optativas são aquelas facultativas, de livre escolha do aluno, para compor o seu currículo de forma a atender uma formação mais personalizada do profissional que está sendo formado.
} 
segundo semestre de 2016. A disciplina, denominada Educação e Sexualidade, teve duração de 34 horas, distribuídas em oito encontros. Os sujeitos de pesquisa foram 13 estudantes, todas do sexo feminino. Por se tratar de uma disciplina optativa, as alunas matriculadas estavam cursando diferentes semestres do Curso de Pedagogia. A turma estava ciente sobre a análise das atividades da disciplina para fins de pesquisa e, voluntariamente, concordaram em participar, sem que a mesma trouxesse prejuízo ou modificações desfavoráveis aos métodos de ensino e ao desempenho das alunas.

O conteúdo programático das aulas, de modo geral, abordou a contextualização histórica da sexualidade, as políticas públicas e as orientações oficiais acerca da educação sexual nas escolas, as modificações fisiológicas do corpo na puberdade, aspectos preventivos, gravidez, sexualidade e cultura, violência sexual, gênero e sexualidade, entre outros aspectos. As atividades desenvolvidas foram diversificadas entre debates, aulas expositivas, dinâmicas de grupo e montagem e desenvolvimento de esquetes teatrais pelas estudantes. Em dois momentos da disciplina foram realizadas avaliações escritas e, a partir delas, selecionamos quatro questões para compor nosso foco de análise, sendo três delas de natureza dissertativa e uma de natureza objetiva. As questões serão apresentadas na próxima sessão deste trabalho, junto aos respectivos resultados e discussões.

As questões dissertativas $(1,2,3)$ buscaram simular situações-problema passíveis de serem enfrentadas durante a futura vida profissional das estudantes, demandando respostas que movimentassem conhecimentos científicos, valores e práticas sociais delas. Enquanto a questão objetiva (4) versou diretamente sobre um conhecimento científico, o qual também pode influenciar práticas sociais requeridas nas demais questões.

Para análise dos dados, optamos por uma associação entre os componentes da triangulação Conhecimentos -Valores - Práticas Sociais (KVP) de Clément (2006), apresentada na revisão bibliográfica deste trabalho, e a Análise de Conteúdo (AC) (BARDIN, 2011). A AC proporciona o levantamento de indicadores que permitem a realização de inferência de conhecimentos (BARDIN, 2011), além do acesso ao repertório semântico ou sintático de determinado grupo social ou profissional (OLIVEIRA, 2008). Assim, a AC emerge como técnica que se propõe à apreensão de uma realidade explícita, mas também de uma realidade invisível, que pode se manifestar apenas nas "entrelinhas" do texto (CAVALCANTE; CALIXTO; PINHEIRO, 2014). Bardin (2011) define três etapas para o processo de análise de conteúdo: i) pré-análise; ii) exploração do material e iii) tratamento dos resultados, inferência e interpretação. 
Ensino, Saúde e Ambiente - V13 (1), pp. 57-83, Abr. 2020

A pré-análise (i) consiste na fase em que se organiza o material a ser analisado com o objetivo de torná-lo operacional, sistematizando as ideias iniciais; enquanto a exploração do material (ii) abarca uma identificação de unidades de registro, construindo uma categorização base. Dessa forma, durante as etapas (i) e (ii) da AC, utilizamos os elementos $\mathrm{K}$, V e P como categorias-base organizativas (categorias a priori). A posteriori, a partir da continuação do processo de Análise de Conteúdo, outras categorias, explícitas e implícitas, foram criadas a fim de melhor elucidar os resultados.

\section{RESULTADOS E DISCUSSÃO}

A maioria dos sujeitos de pesquisa, por se tratarem de estudantes de Curso de Pedagogia Noturno, trabalha durante o dia. São do sexo feminino, com idades que variam entre 19 e 30 anos, pertencentes a classes econômicas e sociais de média a baixa. Na maioria são egressas de escolas públicas, sendo que somente duas, pelo fato de serem religiosas de congregações católicas, estudaram em escolas privadas. Algumas delas atuam como docentes ou monitoras na educação infantil e outras são bolsistas do Programa Institucional de Bolsas de Iniciação à Docência (PIBID) em escolas públicas e privadas. Abaixo, apresentamos as questões analisadas divididas em subtítulos: Transmissão do vírus HIV e implicações sociais; Métodos anticoncepcionais e proteção contra IST; Gravidez na adolescência e sexualidade; Hormônios e ciclo menstrual.

Transmissão do vírus HIV e implicações sociais

Questão 1: Em um ambiente escolar, você se depara com a seguinte situação:Uma criança nasceu com HIV (contaminação vertical de mãe para filho) e este fato se torna conhecido por todos na escola. No entanto, alguns coleguinhas começaram a excluir a criança das brincadeiras, a recusar a usar o mesmo banheiro e compartilhar o refeitório por medo de contaminação. Que atitudes você tomaria, enquanto profissional da educação, tendo em vista esta situação?

Nessa questão foi explorado o tema "transmissão do vírus da imunodeficiência adquirida (HIV)" contextualizado para o ambiente escolar e associado à estigmatização da criança portadora. O caso apresentado corresponde a uma realidade brasileira: $85 \%$ das notificações de infecção pelo HIV em menores de 13 anos têm como modalidade a transmissão de mãe para filho, também chamada de vertical (ARAÚJO et al., 2008).

As formas de transmissão de HIV foram abordadas na disciplina, o que permitiria aos sujeitos da pesquisa formular respostas contendo informações técnico-científicas acerca da temática. Das 13 respostas analisadas, menos da metade $(38,46 \%)$ demonstrou utilização 
de conhecimentos científicos na resolução da situação e, mesmo nesse grupo, foi possível detectar as representações de dois conjuntos de problemas: i) "Nem sempre uma criança com HIV terá AIDS, mas ela pode contaminar outras pessoas mesmo assim.”(sujeito 2); ii) “[...]não é contagioso dividir o mesmo banheiro, refeitório e brincar junto. Somente por contato sexual e compartilhamento de seringas."(sujeito 12). A primeira resposta não traz o contexto necessário de aplicação e, de modo não explícito sugere a problematização da presença de alunos com HIV na escola com a ideia de não ser possível saber quem é portador de HIV. Ao não apresentar solução e escolher uma afirmativa que levanta a possibilidade de que outras crianças contaminadas possam estar frequentando a escola, a resposta revela dificuldade em organizar as informações científicas para superação de problemas. A segunda resposta, ao limitar a transmissão do HIV ao exercício da sexualidade adulta e ao uso de drogas injetáveis, também descontextualiza a situação proposta e lança o problema para uma fase posterior da Educação Básica (Ensino Médio, EJA). Esse afastamento do problema em relação ao cotidiano dos anos iniciais pode ser interpretado como uma rejeição ou dificuldade na abordagem do tema.

Em ambos os casos, não são indicadas soluções para o problema, ainda que informações válidas sobre o HIV tenham sido usadas. É possível relacionar essas respostas com saberes estabelecidos no senso comum e a participação das informações "novas" veiculadas na disciplina sendo usadas dentro de um contexto de opinião pré-estabelecido. A associação do HIV/AIDS com condutas como promiscuidade sexual e uso de drogas foi sedimentada no senso comum através do conceito "grupos de risco" (PARKER; AGGLETON, 2001; MALISKA et al., 2009). As ideias estigmatizantes originadas no início da epidemia, nos anos 80, ainda estão presentes e são consideradas difíceis de serem removidas (LELIS et al., 2016). A substituição da noção de "grupo de risco" por "comportamento de risco" é necessária porque colabora para uma melhor compreensão das medidas de prevenção (GRIEP, ARAÚJO, BATISTA, 2005). Em contextos escolares, ao se trabalhar com "grupos de risco" pode-se acabar passando uma mensagem àqueles que não se reconhecem como pertencentes a esses grupos de que não necessitam de proteção uma vez que se imaginariam fora do alcance de uma contaminação.

As demais respostas afirmaram que as circunstâncias citadas na questão, como brincadeiras infantis, utilização do mesmo banheiro e refeitório, não representavam riscos de transmissão e contágio do/pelo vírus HIV, mas não mencionam nem avançaram na direção da superação de eventuais problemas envolvendo os acidentes que costumam ocorrer no 
ambiente escolar e que podem envolver a exposição de pequenas quantidades de sangue, por exemplo.

Diferente das manifestações do tipo $\mathrm{K}$, todos os 13 sujeitos manifestaram explicitamente componentes $\mathrm{V}$ nas respostas à questão $1 \mathrm{e}$, por meio da análise de conteúdo, identificamos categorias de valores muito positivos: inclusão, empatia e igualdade. $\mathrm{Na}$ maioria das respostas $(53,84 \%)$ o valor inclusão estava explícito ou implícito, sendo a empatia a outra categoria mais frequente $(38,46 \%)$, seguida pelo princípio da igualdade que foi identificado em 23,07\% das respostas. As frases mais representativas das três categorias são respectivamente: "eu explicaria que não devemos excluir o colega", "precisamos nos colocar no lugar do outro", "ele é um ser humano como qualquer outro".

$\mathrm{Na}$ análise do componente $\mathrm{V}$, é possível detectar outro conjunto de "problemas" associados à imagem do portador de HIV, ainda que a base de valores seja essencialmente positiva há alguns trechos de respostas que nos chamaram a atenção, porque associam o portador à condição de doente e/ou destacam uma "isenção de culpa": "levaria todos a entender que o colega adquiriu a doença sem saber, que ele não tem culpa" (sujeito 7).

A situação encontrada nas respostas é concordante com os primeiros resultados de pesquisa sobre a presença de crianças portadoras de HIV no ambiente escolar. Parker e Aggleton (2001) ao analisarem o estigma e a discriminação que os portadores de HIV encontram, também discorrem sobre a ambiguidade das mensagens presentes no âmbito escolar. Há a percepção da condição de "vítimas inocentes" (alunos soropositivos) e, simultaneamente, o medo da comunidade escolar em recebê-los e aceitá-los na escola. A associação estabelecida no senso comum entre HIV/AIDS com "punição e desvio" dos sujeitos soropositivos (PARKER; AGGLETON, 2001; MALISKA et al., 2009) manifesta-se no reconhecimento da "falta de culpa" da criança portadora. Porém, há nesse tipo de manifestação a condenação implícita de adultos e jovens que tenham adquirido o vírus por outras formas de contágio, o que reforça os valores de senso comum desde o início da escolaridade e perpetuam a ideia de que as pessoas são punidas através da infecção/doença, conferindo ao HIV/AIDS um sentido de "castigo e punição" pelo comportamento que os levou à contaminação.

As manifestações de $\mathrm{P}$ propostas pelos sujeitos foram principalmente voltadas para os indivíduos diretamente envolvidos na situação escolar. Conversar com as crianças foi a medida mais lembrada $(84,67 \%)$, um número menor de respostas ampliou resolução do problema proposto incluindo os pais das crianças $(7,69 \%)$ e uma fração menor ainda $(5,38 \%)$ apresentou proposta de envolver a comunidade. 
$\mathrm{O}$ conjunto de resultados sobre a presença de componentes $\mathrm{K}, \mathrm{V}$ e $\mathrm{P}$ nas respostas da questão 1 permite a seguinte interpretação: os sujeitos, quando postos em situação de profissionais da educação, conversariam com as crianças embasados em seus próprios valores, compondo uma categoria de P implícita que chamamos de "discurso de valores". De acordo com Araújo e Camargo (2004), não basta informar os jovens, pois os métodos tradicionais de comunicação e educação em saúde (realização de palestras, distribuição de folhetos informativos, etc.) têm-se mostrado pouco eficazes, exigindo outra forma de abordagem e uso da linguagem mais dinâmica e lúdica, que atinja, efetivamente, esses sujeitos.

Além disso, 46,15\% afirmaram que ao invés de elas próprias resolverem a situação, chamariam outras pessoas para palestrar na escola, como médicos, enfermeiros e psicólogos. Tal dado pode ser interpretado como uma rejeição do tema educação sexual ou como falta da noção de "pertencimento" em relação ao tema, propondo a transferência da solução do problema para os profissionais da saúde. Acionar profissionais da enfermagem, medicina ou psicologia para apresentar palestras sobre educação sexual, mais do que trazer saberes especializados para a escola, pode ter o significado de desobrigar os professores de trabalharem de modo transversal e integrado sobre o tema e, ainda, de adquirem conhecimentos científicos acerca do assunto. Associamos esse comportamento a uma categoria de baixa autoestima profissional, na qual os profissionais de educação sentem-se pouco preparados ou menos capazes de aprenderem e ensinarem acerca de temas envolvendo corpo humano e saúde e, ainda, aspectos sociais ligados à sexualidade.

A esse respeito, destacamos dois estudos internacionais, os quais também utilizaram como base teórica a estrutura KVP de Clément e apresentam resultados semelhantes aos nossos. Um deles, realizado no Marrocos (SABAH et al., 2010) e outro em Camarões (NCHIA et al., 2015), destacam concepções de professores primários e secundários sobre a educação sexual. Nessas pesquisas, os professores primários, assim como em nossos achados, também afirmam ser papel dos profissionais de saúde orientar os estudantes quanto à educação sexual, com destaque às IST e aos aspectos psicossociais. A maioria dos professores secundários investigados, principalmente os de Biologia, no entanto, reivindica para si essa responsabilidade. Ambos os grupos de pesquisa chegam à mesma conclusão: há grande importância em investir na formação dos professores primários para que esses também se sintam preparados e responsáveis por abordar a educação sexual desde os primeiros anos de escolaridade.

Métodos anticoncepcionais e prevenção contra IST 
Ensino, Saúde e Ambiente - V13 (1), pp. 57-83, Abr. 2020

Questão 2: A Academia Americana de Pediatria publicou uma diretriz apontando que os métodos de contracepção prolongada, como o DIU, não são usados pelos jovens, mesmo sendo mais eficientes. A academia reforçou que esses procedimentos podem ser utilizados por adolescentes. Os dados mostram ainda que $22 \%$ das meninas tentam utilizar o método do coito interrompido, que tem um índice de eficácia muito baixo.2.1 Enquanto profissional da educação, o que você dirial explicaria aos jovens em relação aos métodos contraceptivos e de prevenção em geral? 2.2. Quais problemas a utilização do DIU como método de prevenção ainda poderia trazer para as jovens? 2.3. Por que o "coito interrompido" apresenta uma baixa eficácia enquanto método contraceptivo?

A segunda questão tem como tema dois métodos contraceptivos que não previnem IST. A participação masculina na prática desses métodos, especialmente na escolha pelo coito interrompido, não foi mencionada intencionalmente. Os objetivos dessa questão foram: i) identificar quais informações seriam priorizadas na composição de uma explicação sobre os métodos de contracepção e de prevenção de IST e a associação entre eles; ii) verificar se as professoras também envolveriam os indivíduos do sexo masculino nas decisões acerca das escolhas de métodos de prevenção de IST ou de métodos contraceptivos. O papel de ambos os gêneros, homens e mulheres, na prevenção de gravidez e IST foi tema discutido em aula, especialmente porque se observa na atualidade brasileira uma forte tendência de atribuir apenas à mulher a incumbência de implementação e gerenciamento de métodos contraceptivos (NICOLAU et al. 2010).

Em relação aos conhecimentos $(\mathrm{K})$ demonstrados na questão, apenas 2 respostas $(15,38 \%)$, mencionaram o fato do DIU não proteger contra IST o que sinaliza a necessidade de desenvolver melhor as informações sobre a importância da proteção contra IST para as mulheres que optam por esse método contraceptivo. Em uma resposta (7,69\%) apareceu a ideia do DIU "se perder no útero da menina", demonstrando desconhecimento acerca desse método e da anatomia feminina.

Sobre a contracepção por meio de coito interrompido, cinco respostas $(38,46 \%)$,reconheceram o método como não eficiente, mas utilizaram como principal justificativa: "o líquido lubrificante que sai do pênis antes da ejaculação pode conter espermatozóides" (sujeito 12). O líquido lubrificante em questão, produzido nas glândulas bulbouretrais (glândulas de Cowper), possui função de lubrificação e esterilização da uretra no período pré-ejaculatório e não contém espermatozóides (NETTER, 2001). No entanto, é aceita, ainda que com cautela, a possibilidade desse líquido "carregar" alguns espermatozóides que já estariam na uretra devido a ejaculações ocorridas logo anteriormente (JONES et al., 2009). Essas informações foram discutidas em aula, juntamente com o fato da dificuldade de se garantir uma ejaculação totalmente externa durante o ato sexual, 
especialmente entre adolescentes. Assim, foi tratado em aula que essa última representaria a principal causa da ineficácia do coito interrompido enquanto método anticoncepcional (ZEKERMAN; WEISS; OVIERTO, 2003), mas somente um (7,69\%) dos sujeitos a mencionou.

Três categorias de valor (V) foram identificadas nas respostas sobre métodos contraceptivos: segurança (em 38,46\% das respostas); estereótipo de gênero $(38,46 \%)$ e, novamente, como observado nas respostas da questão 1, a categoria baixa autoestima profissional foi a mais frequente $(69,23 \%)$. Em algumas respostas é possível observar a associação das três categorias: "sobre os métodos de prevenção eu diria para as adolescentes (estereótipo de gênero) quando decidissem começar a ter relações sexuais para procurar um médico ginecologista (baixa autoestima profissional) para ficarem mais seguras sobre o que vão fazer (segurança)".

Os valores estereótipo de gênero e baixa autoestima profissional possuem estreita relação com as práticas sociais $(\mathrm{P})$ também detectadas. Identificamos o $\mathrm{V}$ baixa autoestima profissional nos mesmos nove sujeitos $(69,23 \%)$ cujas respostas continham recomendações (P) para que os jovens procurassem um profissional da área da saúde, caso quisessem informações acerca dos métodos de prevenção, tanto de gravidez, como de IST. Assim, a categoria de V baixa autoestima profissional foi considerada implícita a partir da categoria de P explícita que recomenda, sem nenhuma tentativa de explicação ou ensino, sobre métodos contraceptivos por parte dos profissionais da educação. A resposta do sujeito 8 é um exemplo bem elucidativo da prática social $(\mathrm{P})$ de recomendar que um profissional da saúde fale com os jovens, simbolizando um quadro de certa desvalorização da própria profissão em detrimento da área médica: "aconselharia que elas fossem no médico ginecologista, pois só eles é que podem indicar e explicar o melhor para cada pessoa".

Não é nossa intenção, no entanto, criticar a prática de se recomendar a procura de um profissional de saúde, mas problematizar a falta de ação dos profissionais da educação em corroborarem com o esclarecimento dos jovens acerca do assunto. Para Ojeda (2004), o saber médico é legitimado socialmente constituindo-se em status privilegiado em relação às demais categorias profissionais, provocando o fenômeno de "silenciamento" de outras profissões dentro e fora da área da saúde. Sob esse ponto de vista, a P que emerge nas respostas está alinhada ao senso comum e seria necessário mais do que a apresentação de informações sobre saúde ou discussão de temas relacionados à saúde na formação docente inicial em direção à valorização da própria formação. 
A $\mathrm{P}$ de encaminhamento à profissional da saúde também possui estreita relação com os estereótipos de gênero, outro V identificado em 53,84\% das recomendações. As recomendações foram para procura de médicos ginecologistas, isentando os meninos da responsabilidade de prevenção de ISTs e do uso de métodos contraceptivos. É exemplo de resposta com esse valor: "eu aconselharia principalmente as meninas a procurarem um médico[...]"(sujeito 12). Essa percepção detectada nas respostas corresponde à "norma contraceptiva" descrita por Bajos, Ferrand e Hassoun (2002) a qual dá conta de cobrar da mulher a responsabilidade pela contracepção, ainda bastante submetida à capacidade de autodeterminação e de negociação com o parceiro. Como surgimento da contracepção médica (pílula, DIU), a medicalização da sexualidade e da reprodução difundiram um conjunto de prescrições às mulheres, sugerindo determinado comportamento reprodutivo. No entanto, segundo as autoras, as mulheres enfrentam constrangimentos para cumprirem essas normas, advindos da permanência da hierarquia de gênero. Por serem mulheres e, assim, também estarem sob o "efeito social" de tal norma contraceptiva, acreditamos que as estudantes perpetuam a ideia da responsabilização feminina pela contracepção refletindo essa demanda em suas práticas sociais. Considerando a pesquisa de Heilborn et al. (2002), caberia aos adultos de referência (pais, professores) a desconstrução da assimetria existente entre os gêneros, a qual a literatura assinala ser uma característica da cultura brasileira e que dificulta a negociação do uso de contraceptivos e práticas preventivas entre parceiros, afirmando-se assim como um dos cofatores de risco que predispõem a uma gravidez na adolescência e às infecções sexualmente transmissíveis. $\mathrm{O}$ fato da maioria das respostas obtidas no presente trabalho usar como norma a responsabilidade feminina sobre a concepção indica que as discussões ou contextualizações sobre o tema, durante a formação inicial de professores, não surte efeito sobre valores construídos previamente e que é necessário o desenvolvimento de abordagens alternativas, se a intenção for modificar o conjunto K-V- P.

Outra $\mathrm{P}$ detectada nas respostas foi a recomendação do uso de preservativo masculino $(30,76 \%)$ e uso de anticoncepcionais orais pelas meninas (61,53\%). Destacamos, novamente, a presença de um discurso de valores $(\mathrm{P})$, categoria de prática social implícita. Nesse sentido, mais uma vez chama a atenção o fato das estudantes apenas recomendarem o uso sem maiores explicações sobre as implicações de cada método, baseando suas práticas pedagógicas muito mais em valores e deixando o conhecimento científico para ser abordado pelos profissionais da saúde, principalmente pelos médicos.

Gravidez na adolescência e sexualidade 
Questão 3: Autores destacam que adolescentes têm desenvolvido um imaginário "assustado" em relação ao exercício da vida sexual e, muitas vezes, acabam relacionando a gravidez na adolescência a um momento de tristeza e abandono da jovem grávida. Esse fato estaria relacionado ao modo como adultos têm agido na chamada "educação sexual". No entanto, continuam a ocorrer altos índices de gestação na adolescência e contaminações por infecções sexualmente transmissíveis. Nesse sentido, Santos e Carvalho (2006) destacam que se, por um lado, preocupa a constatação de que praticamente metade dos jovens brasileiros tem iniciado sua vida sexual sem a adoção de nenhum método contraceptivo, por outro, entende-se como problemáticos os programas de educação sexual que, pela via do "terror", visam "cuidar" da sexualidade dos adolescentes. Diante dessa perspectiva, acredita-se na possibilidade de o adolescente ser alertado acerca das consequências inerentes à vida sexual desprotegida, sem, no entanto, ter a sua sexualidade "aniquilada" ou ser eximido do direito a uma vida sexual plena (ORLANDI; TONELLI, 2008). Como você, enquanto profissional da educação, acredita ser viável alcançar essa possibilidade?

A questão explora duas situações conflitantes: os índices de gravidez e IST entre os jovens e desenvolvimento da sexualidade adolescente. Foram identificados $\mathrm{K}$ em manifestações de apenas 15,38\% delas:“[...]a importância de exames pré-natais para identificação precoce de problemas com a criança [...]” (Sujeito 2) e “[...] ISTs como a sífilis, causada por uma bactéria e representa uma epidemia [...]” (Sujeito 4).Os V explícitos identificados nas respostas foram: coletividade e colaboração (30,76\%): "[...]não é um trabalho isolado, precisa da colaboração de todos, pais, escola [...]”(Sujeito 3); conscientização (38,46\%): “[...] como campanhas de conscientização em sala de aula [...]" (Sujeito 9); esclarecimento (23,07\%): “[...] Jelaborar folhetos explicativos, usar estatísticas [...]” (Sujeito 13); alerta (15,38\%): “[...]para alertar sobre as doenças [...]” (Sujeito 4); cuidado (7,69\%): “[...] levando os conhecimentos necessários para que passem a cuidar de si mesmos.” (Sujeito 1); risco (30,76\%): “[...]é preciso explicar os riscos [...]”(Sujeito 2); e combate à gravidez na adolescência (15,38\%): “[...] medidas para combater a gravidez na adolescência [..]” (Sujeito 9).

Além disso, percebemos um $\mathrm{V}$ implícito que denominamos de visões sobre a juventude $(53,84 \%)$, o qual pode ser dividido em visão de desvio (abrange aqueles que acreditam que jovens são seres que desviam de certo padrão normativo, 30,76\%) e impulsos (abrange as respostas sobre jovens como seres emocionais e não racionais, 23,07\%). Em relação a este valor implícito as estudantes expressam a ideia, bastante difundida no imaginário social, dos jovens como sujeitos inconsequentes e impulsivos, os quais precisam 
ser auxiliados e orientados para um padrão comportamental aceitável entre adultos: "jovens não conseguem discernir prioridades, agem com paixão" (sujeito 10), "[...]porque os adolescentes não tem consciência do que estão fazendo pois são inconsequentes [...]não pensam no futuro[...]”(sujeito 17), “[...] é necessário guiá-los para que passem por essa fase [...]”(sujeito 9). Essa percepção sobre o período da juventude é vigente na sociedade e vários autores (SPOSITO, 2002; CAMARANO et al., 2004; DAYRELL, 2007) indicam que a ideia mais frequente é a condição de transitoriedade reduzindo essa fase da vida a uma preparação para a vida adulta.

Sposito (2002) critica a ideia de transitoriedade em dois aspectos, sendo um deles a percepção de transição como indeterminação, na qual os jovens não são mais crianças, mas também não são adultos, desqualificando esse momento da vida, exatamente por se tratar apenas de uma passagem. O segundo aspecto incide sobre uma necessária subordinação dessa fase à vida adulta, que seria uma referência normativa máxima de estabilidade em contraste ao período de instabilidade e crises da juventude (SPOSITO, 2002). Segundo Dayrell (2007), a escola como instituição que fornece através do diploma, um passaporte para o futuro, tende a negar o presente e as questões existenciais vividas pelo jovem como espaço válido de formação.

As respostas sobre gravidez na adolescência indicam como abordagem do problema o desenvolvimento de um trabalho coletivo entre escola e família e, ainda, entre professores e profissionais de saúde (53,84\%): "é necessário trabalhar com profissionais da saúde, visitar e conhecer as famílias [...]"(sujeito 11). Nessas respostas não houve uma intenção de transferir a tarefa para a área da saúde, talvez porque não foram exigidos conhecimentos específicos de fisiologia, bioquímica ou anatomia. As respostas, no entanto, trazem ideias relacionadas apenas à conscientização, esclarecimento e alerta sobre riscos, visando ao "combate” à gravidez na adolescência, contradizendo as considerações apresentadas no enunciado da questão.

De modo objetivo, nenhuma estudante respondeu a questão afirmando ser possível conciliar ações de prevenção e contracepção com uma vida sexual ativa na adolescência. Interpretamos esse dado a partir de duas explicações: a) fuga do tema por ainda considerarem o início da vida sexual na adolescência um tabu, não se sentindo à vontade para emitirem opiniões e explicações ou b) apresentarem uma opinião contrária ao que foi exposto no enunciado, mas, em momento de avaliação, sentiram-se constrangidas em manifestarem o desacordo com as ideias do autor. Em relação ao item a, Witter e Guimarães (2008) trazem que muitos adultos como pais e professores acreditam na falsa ideia de que, se não falarem 
sobre sexualidade com os jovens, eles não despertarão para o tema, mantendo o assunto como um tabu. Quanto ao item b, entendemos a estratégia utilizada e respeitamos a posição das estudantes em procurarem uma solução para questão sem contradizerem seus próprios valores.

As P explícitas identificadas foram diálogo $(69,23 \%)$, palestras $(38,46 \%)$, trabalho coletivo $(23,07 \%)$ e campanhas de conscientização $(23,07 \%)$. Além disso, assim como nas questões 1 e 2, a P implícita denominada discurso de valores $(61,53 \%)$ foi identificada. Destacamos a categoria diálogo, que aparece como uma relação horizontal entre docente e alunos que discutiriam acerca da gravidez na adolescência (mas não sobre exercício seguro da sexualidade).A palestra está em segundo lugar como $\mathrm{P}$ indicando que, entre as principais abordagens da questão, está o esclarecimento com auxílio de especialistas. As outras manifestações de $\mathrm{P}$ encontradas nas respostas revelam a compreensão da complexidade do problema e envolvem a comunidade escolar de modo mais amplo.

\section{Hormônios e ciclo menstrual}

Questão 4: Os hormônios sexuais provocam alterações comportamentais e físicas nos indivíduos, principalmente na puberdade, período em que os jovens passam boa parte do tempo no ambiente escolar.

A partir da puberdade, o corpo feminino está apto para a reprodução. O corpo, a cada mês, se preparará para receber um embrião em seu útero. Caso isso não ocorra, acontecerá a menstruação. Sobre a menstruação, marque a alternativa incorreta.

a) A menstruação é a eliminação da parede mais externa do útero (endométrio), juntamente ao sangue.

b) A menstruação representa o período fértil da mulher.

c) A menstruação ocorre quando há uma baixa na produção dos hormônios femininos.

d) Quando ocorre a gravidez, a menstruação é impedida graças à manutenção da taxa hormonal.

Utilizamos a questão objetiva para avaliar conhecimentos gerais acerca da menstruação e a frequência de acertos foi de $46,15 \%$. Entre as que não escolheram a alternativa "b" como incorreta, portanto não acertaram a questão, tivemos $23,07 \%$ escolhendo “a”, 15, 38\% marcando "c", 7,69\% assinalando a "d" e 7,69\% deixando em branco a questão. Ao não reconhecerem a afirmação "A menstruação representa o período fértil da mulher" como incorreta as estudantes podem enfrentar dois obstáculos: o primeiro enquanto mulheres que decidem por algum tipo de contracepção e o segundo enquanto educadoras que buscam ensinar tal conhecimento aos seus alunos.Em um estudo antropológico sobre saúde feminina, Leal (1994) demonstrou ser recorrente no imaginário popular a associação entre sangue da 
menstruação e fertilidade como uma analogia direta com o esperma masculino. Mais recentemente, em uma investigação com população de Ensino Médio, Bastos (2015) descreve a presença de explicações alternativas para o processo de menstruação (eliminação de óvulos velhos, a limpeza do útero, explicações religiosas) e, novamente, a relação menstruaçãoperíodo fértil da mulher.

Nossos achados evidenciam a insuficiência da aprendizagem ao longo da escolaridade, assim como a falha das vivências pessoais em romper com o senso comum acerca da fisiologia do ciclo menstrual e, provavelmente, do processo de gestação. As respostas obtidas são o produto da deficiência da escola em tratar aspectos básicos de educação sexual e também expressam a dificuldade da educação superior em modificar concepções prévias nessa área.

No quadro 1 apresentamos um resumo das categorias organizativas a priori $\mathrm{K}, \mathrm{V}$ e $\mathrm{P}$ com a composição das demais categorias a posteriori percebidas na análise dos dados, tanto explícitas, quanto implícitas. Ainda, de acordo com Clément (2006), realizamos uma separação no componente $\mathrm{K}$, descrevendo os conhecimentos como científicos e aqueles conhecimentos que se afastam do científico.

\begin{tabular}{|c|c|c|c|c|c|}
\hline \multirow[t]{2}{*}{ Categoria } & \multirow[t]{2}{*}{ Questão } & \multicolumn{2}{|c|}{ Conhecimento (K) } & \multirow[t]{2}{*}{ Valores (V) } & \multirow[t]{2}{*}{ Práticas Sociais $(\mathbf{P})$} \\
\hline & & Científico & $\begin{array}{c}\text { Afastado do } \\
\text { científico }\end{array}$ & & \\
\hline \multirow{3}{*}{ Explícita } & 1 & $\begin{array}{l}\text {-Ter HIV é } \\
\text { diferente de ter } \\
\text { AIDS. } \\
\text { - Não se transmite } \\
\text { HIV em } \\
\text { brincadeiras } \\
\text { infantis, uso do } \\
\text { mesmo banheiro e } \\
\text { refeitório. }\end{array}$ & $\begin{array}{l}\text {-Ter HIV } \\
\text { representa estar } \\
\text { doente de AIDS. - } \\
\text { HIV se transmite } \\
\text { apenas por contato } \\
\text { sexual e } \\
\text { compartilhamento } \\
\text { de seringas }\end{array}$ & $\begin{array}{l}\text {-Inclusão, } \\
\text {-Igualdade, } \\
\text {-Empatia. }\end{array}$ & $\begin{array}{l}\text {-Conversas com } \\
\text { alunos, pais e } \\
\text { comunidade escolar, } \\
\text { - Explicação das } \\
\text { formas de contágio } \\
\text { do HIV. }\end{array}$ \\
\hline & 2 & $\begin{array}{l}\text { - Há possibilidades } \\
\text { de gravidez pelo } \\
\text { líquido } \\
\text { ejaculatório e pela } \\
\text { dificuldade de } \\
\text { ejaculação externa } \\
\text { na utilização do } \\
\text { coito interrompido. } \\
\text {-A utilização do } \\
\text { DIU não previne } \\
\text { IST }\end{array}$ & $\begin{array}{l}\text { - O DIU pode se } \\
\text { perder no corpo da } \\
\text { mulher }\end{array}$ & -Segurança & $\begin{array}{l}\text {-Recomendações } \\
\text { para a procura de } \\
\text { médicos } \\
\text { especialistas; para o } \\
\text { uso de preservativo } \\
\text { masculino } \\
\text { (camisinha) e uso de } \\
\text { anticoncepcional } \\
\text { oral (pílula); } \\
\text { - Explicações sobre } \\
\text { as limitações do } \\
\text { método coito } \\
\text { interrompido e DIU }\end{array}$ \\
\hline & 3 & $\begin{array}{l}\text {-Exames pré-natais } \\
\text { podem identificar } \\
\text { precocemente } \\
\text { problemas de }\end{array}$ & & $\begin{array}{l}\text { - Coletividade, - } \\
\text { colaboração, - } \\
\text { conscientização, } \\
\text {-esclarecimento, - }\end{array}$ & $\begin{array}{l}\text {-Diálogo,-palestras, - } \\
\text { trabalho coletivo, - } \\
\text { campanhas de } \\
\text { conscientização }\end{array}$ \\
\hline
\end{tabular}


Ensino, Saúde e Ambiente - V13 (1), pp. 57-83, Abr. 2020

\begin{tabular}{|c|c|c|c|c|c|}
\hline & & $\begin{array}{l}\text { saúde no feto. } \\
\text { - Sífilis é causada } \\
\text { por bactéria e } \\
\text { representa uma } \\
\text { epidemia. }\end{array}$ & & $\begin{array}{l}\text { alerta, -cuidado,- risco, } \\
\text {-combate à gravidez } \\
\text { na adolescência }\end{array}$ & \\
\hline & 4 & $\begin{array}{l}\text { - A menstruação } \\
\text { não representa o } \\
\text { período fértil da } \\
\text { mulher. }\end{array}$ & $\begin{array}{l}\text { - Há relaçãa entre a } \\
\text { menstruação e o } \\
\text { período fértil da } \\
\text { mulher }\end{array}$ & & \\
\hline \multirow{4}{*}{ Implícita } & 1 & & $\begin{array}{l}\text {-Ausência de } \\
\text { clareza sobre a } \\
\text { relação HIV/AIDS, } \\
\text {-Fragmentação do } \\
\text { conhecimento } \\
\text { acerca das formas } \\
\text { de transmissão do } \\
\text { HIV. }\end{array}$ & $\begin{array}{l}\text { Culpabilização dos } \\
\text { portadores de HIV, } \\
\text { baixa autoestima } \\
\text { profissional, professor } \\
\text { como centro do } \\
\text { processo educacional, } \\
\text { preconceito. }\end{array}$ & $\begin{array}{l}\text { Discurso de valores } \\
\text { próprios, } \\
\text { terceirização da } \\
\text { resolução de } \\
\text { problemas para a } \\
\text { área da saúde. }\end{array}$ \\
\hline & 2 & & $\begin{array}{l}\text { Ausência de clareza } \\
\text { acerca da anatomia } \\
\text { feminina }\end{array}$ & $\begin{array}{l}\text { Estereótipo de gênero; } \\
\text { baixa autoestima } \\
\text { profissional }\end{array}$ & Discurso de valores \\
\hline & 3 & & & $\begin{array}{l}\text { Visões sobre a } \\
\text { juventude: desvio e } \\
\text { impulsividade }\end{array}$ & Discurso de valores \\
\hline & 4 & & $\begin{array}{l}\text { Ausência de clareza } \\
\text { sobre o ciclo } \\
\text { menstrual. }\end{array}$ & & \\
\hline
\end{tabular}

Quadro 1 - Categorias de Conhecimentos, Valores e Práticas Sociais identificadas nas questões 1, 2, $3 \mathrm{e}$ 4.

Fonte: As autoras

A análise dos quatro conjuntos de respostas permite destacar que, embora os elementos de Prática Social (P) estejam sempre presentes nas respostas de todas as estudantes (exceto na questão 4 por ser objetiva), na maioria das vezes, o problema apresentado é apenas tangenciado, sem proposta de abordagem efetiva ou direta. Em parte, isso pode ser explicado pela situação de aplicação hipotética, em um contexto idealizado, criado para fins de avaliação em uma disciplina. Porém, as $\mathrm{P}$ identificadas nas respostas indicam a necessidade de outros tipos de intervenção para que as práticas escolares sejam efetivadas de fato no futuro e busquem, de forma real, resolver os problemas apresentados.

Em relação ao componente Conhecimento $(\mathrm{K})$ percebemos que foram proferidos pontualmente por algumas estudantes e também que se mostram de forma sutil dentro do discurso. Nota-se ainda, manifestações de conhecimentos afastados dos científicos, o que pode denotar uma sensação, por parte das estudantes, de suficiência das explicações prévias ou de senso comum para a resolução das questões, mesmo quando os conhecimentos científicos necessários foram discutidos e apresentados na disciplina. Nesse caso, o foco das investigações sobre como melhorar a inclusão da temática sexualidade na educação básica deve ser modificado. É fato a necessidade de aumentar o nível de aprendizagem dos professores, visando um empoderamento por meio do qual se sintam mais próximos em termos de conhecimentos aos palestrantes que usualmente são convidados. Mas isso não basta 
se não entendermos como e por que as informações tidas como Conhecimento Científico são relegadas a um segundo plano no discurso, pois só são apresentadas se forem explicitamente solicitadas e, ainda assim, podem se afastar do conhecimento científico.

Resultados semelhantes são relatados por Silva e Megid Neto (2006); ao analisarem as produções de pós-graduação brasileiras sobre formação de professores/educadores para o trabalho com Educação Sexual nos vários níveis escolares, esses autores também concluem que as concepções dos professores se encontram ao nível do senso comum, perpetuando valores e preconceitos relacionados à sexualidade. Esse não é um fenômeno restrito à educação brasileira. Na pesquisa já mencionada no trabalho, realizada em Marrocos (SABAH et al., 2010), os autores concluíram que as concepções dos professores acerca da sexualidade e da educação sexual estão profundamente enraizadas mais nos sistemas de valores que no conhecimento científico e, além disso, que há uma recusa em ampliar a abordagem da educação sexual para além das questões de biologia e saúde.Na pesquisa com professores camaroneses, Nchia e colaboradores (2015) chegam às mesmas conclusões sobre concepções e práticas dos professores baseadas em valores e apresentam dois questionamentos, os quais podem ser repensados para a realidade brasileira: i)como responder à pressão social e ao desenvolvimento da cidadania apropriada nesse cenário de abstenção à informação científica? ii) que abordagens devem ser privilegiadas na formação docente para estimular a aquisição e a valorização de conhecimentos e competências em relação à educação sexual e promovam a superação das diferenças culturais que levam a atitudes de preconceito e exclusão?

Por fim, o conjunto de resultados permite generalizar que, para alcançar Práticas Sociais alinhadas com os princípios de inclusão e respeito à diversidade, valorização da vida e desenvolvimento pleno do ser humano, é necessário, na formação docente, dedicar esforços:

1) na identificação dos Valores presentes nas crenças e visões de mundo dos profissionais em formação, para reconhecer quando e como é necessário investir na mudança de cenários de preconceito e esteriotipação;

2) no processo de ensino-aprendizagem conceitual de modo a integrar os Conhecimentos Científicos às Práticas Sociais para que estas não sejam fundamentadas exclusivamente em Valores ou em conhecimentos de senso comum. A identificação de valores pode ser considerada base para o sucesso na aprendizagem conceitual, pois, de acordo com Clément (1998), crenças e opiniões são obstáculos mais resistentes que lacunas no conhecimento científico. 
Ensino, Saúde e Ambiente - V13 (1), pp. 57-83, Abr. 2020

\section{CONSIDERAÇÕES FINAIS}

Por meio deste trabalho buscamos identificar quais são e como inter-relacionam-se os conhecimentos $(\mathrm{K})$, os valores $(\mathrm{V})$ e as práticas sociais $(\mathrm{P})$ de estudantes de Pedagogia no que diz respeito à sexualidade e ao trabalho com educação sexual quando transpostos em ambiente escolar. Para tanto, apresentamos alguns problemas práticos, passíveis de serem encontrados no dia-a-dia de uma escola, como o convívio com pessoas portadoras do vírus HIV, aspectos sociais da gravidez na adolescência, dúvidas dos jovens quanto aos métodos de prevenção de infecções e contracepção e sobre a fisiologia do sistema reprodutor feminino.

Como resultados, destacamos uma incipiência na utilização dos $\mathrm{K}$ por parte das estudantes, as quais forneceram respostas mais opinativas, embasadas muito mais em seus $\mathrm{V}$. Ainda, alguns $\mathrm{K}$ demonstraram estarem afastados dos conhecimentos científicos. Dessa forma, também nos interessou analisar qualitativamente tais V e P, uma vez que, sendo a sexualidade uma temática considerada controversa, abre-se a oportunidade de interpretações pessoais dos mais diversos tipos. Assim, encontramos algumas manifestações de estigmatização dos sujeitos portadores de HIV e também estereótipos de gênero, ao demonstrarem aceitar ser a contracepção uma responsabilidade unicamente feminina. Destacamos ainda, o que interpretamos como um $\mathrm{V}$ de baixa autoestima profissional, pois, na ausência de $\mathrm{K}$, as estudantes recomendaram que os jovens procurassem sanar suas dúvidas com profissionais da saúde, abstendo-se do papel que a educação sexual, a partir da escola, pode exercer na vida dos estudantes por meio do acesso e do aprofundamento dos conhecimentos científicos.

Nesse sentido, o modelo KVP nos mostra que a atividade educativa, a partir do processo de transposição didática, carrega consigo uma intencionalidade de aprendizagem que pode transcorrer a partir de seus três polos. No entanto, alguns desses polos, dependendo da situação apresentada, podem ser mais acionados que outros. A proposta para formação inicial de pedagogos pautada em uma aprendizagem conceitual contextualizada, direcionada por meio de atividades alicerçadas em análise, discussão e resolução de situações problemas reais na atuação profissional, também pode ser considerada promissora. No processo de resolução das situações foi possível evidenciar os valores que estão em uso, as lacunas de conhecimento que devem ser superadas e quais são os possíveis resultados na abordagem do problema dentro do contexto percebido pelos participantes. As várias alternativas para Práticas Sociais devem emergir ao final das discussões e a avaliação da viabilidade e a adequação ética de cada uma delas pode ser explorada segundo o contexto proposto. 
Para tanto, defendemos a ampliação do diálogo acerca da sexualidade no contexto de formação de pedagogos, buscando, além dos aspectos de valores e práticas sociais já mencionados, a valorização dos conhecimentos científicos, especialmente aqueles oriundos da biologia, tendo em vista a importância da atuação desses profissionais na gestão, no apoio didático-pedagógico, na orientação educacional que desempenham, e possuem potencial para desempenhar, no ambiente escolar desde os primeiros anos escolares, em relação à temática.

\section{REFERENCIAS:}

ALTMANN, H. A. Orientação sexual em uma escola: recortes de corpos e de gênero.

Cadernos Pagu, Campinas, n.21, p.281-315, 2003. Disponível

em:<http://www.scielo.br/scielo.php?pid=S0104-

83332003000200012\&script=sci_abstract\&tlng=pt>. Acesso em: 10 set. 2017.

ALTMANN, H. A. Sexualidade adolescente como foco de investimento político-social.

Educação em Revista, Belo Horizonte, n.46, 2007. Disponìvel

em:<http://www.scielo.br/scielo.php?pid=S0102$46982007000200012 \&$ script $=$ sci_abstract\&tlng=pt $>$. Acesso em: 03 set. 2017.

ARAÚJO, C. L. F.; CAMARGO Jr., K. R. Aconselhamento em DST/ HIV: repensando conceitos e prática. Rio de Janeiro: Folha Carioca; 2004.

ARAUJO, E. S. N. N. de.; CALDEIRA, A. M. de A.; CALUZI, J. J.; CARVALHO, G. S. Concepções criacionistas e evolucionistas de professores em formação e em exercício. Atas do VII ENPEC, Anais, Florianópolis, 2009. Disponível em:

$<$ http://posgrad.fae.ufmg.br/posgrad/viienpec/pdfs/1186.pdf > . Acesso em: 03 set. 2017.

ARAÚJO, M. A. L.; SILVEIRA, C. B. da.; SILVEIRA, C. B. da.; MELO, S. P. de. Vivências de gestantes e puérperas com o diagnóstico do HIV. RevBrasEnferm, Brasília, n. 61, v. 5, 2008. p. 589-94. Disponível

em: $<$ http://www.scielo.br/scielo.php?script=sci_arttext\&pid=S0034-71672008000500010 $>$. Acesso em; 16 set. 2107.

ARRUDA, V. R. G. Formação de educadores(as) sexuais no Ensino Fundamental. Maringá: Secretaria de Estado da Educação, 2008.

ASTOLFI, J. P.; DEVELAY, M. A didática das ciências. Campinas, SP: Papirus Editora, $6^{\text {a }}$ Ed., 2001.

BAJOS, N.; FERRAND, M.; HASSOUN, D. Au risque de l'échec:

lacontraceptionauquotidien. In: De lacontraception à l'avortement. Sociologiedesgrossesses non prévues. Paris: Editions INSERM, p.33-78, 2002.

BARDIN, L. Análise de Conteúdo. Edição revista e ampliada. Pt: Edições 70 Brasil, 2011.

BASTOS, G. D. Biologia no Ensino Médio: diferentes abordagens metodológicas para adequar o conhecimento ao cotidiano - enfoque sobre a gravidez na adolescência.

Dissertação (Mestrado em Educação em Ciências) - Centro de Ciências Naturais e Exatas.

Universidade Federal de Santa Maria. Santa Maria. p. 174. 2015.

BRASIL. Plano Nacional de Educação 2011- 2020 (PNE). Ministério da educação e

Cultura, 2011. Disponível em:<http://www.planalto.gov.br/ccivil_03/_ato2011-

2014/2014/lei/113005.htm>. Acesso em: 20 set, 2017.

BRASIL, Lei de Diretrizes e Bases para a Educação Nacional no 9394, de 23 de dezembro de 1996. Disponível em:<http://www.planalto.gov.br/ccivil_03/leis/L9394.htm>. Acesso em: 27 Jul. 2017.

BRASIL. Secretaria de Educação Fundamental. Parâmetros curriculares nacionais: pluralidade cultural, orientação sexual. Brasília: MEC/SEF, 1997. 
CAMARANO, A. A.; MELLO, J.; PASINATO, M. T.; KANSO, S. Caminhos para a vida adulta: as múltiplas trajetórias dos jovens brasileiros. Revista Última Década, v.12, n.21, Santiago dic., 2004.

CARDOSO, F. L. O conceito de orientação sexual na encruzilhada entre sexo, gênero e motricidade. Interam. j. psychol. v.42 n.1, 2008.

CARVACHO, I. E.; SILVA, J. L. P.; MELLO M., B. Conhecimento de adolescentes grávidas sobre anatomia e fisiologia da reprodução. Revista da Associação Médica Brasileira, São Paulo, v.54, n.1, p.29-35, 2008. Disponível

em:<http://www.scielo.br/scielo.php?script=sci_arttext\&pid=S0104-42302008000100017>. Acesso em: 15 set. 2017.

CARVALHO, M. E.; ANDRADE, F.; MENEZES, C. (orgs.). Equidade de gênero e diversidade sexual na escola: por uma prática pedagógica inclusiva. João Pessoa: Universitária/UFPB, 2009.

CAVALCANTE, R. B.; CALIXTO, P.; PINHEIRO, M. K. Análise de conteúdo: considerações gerais, relações com a pergunta de pesquisa, possibilidades e limitações do método. Inf. \&Soc.:Est., João Pessoa, v.24, n.1, p. 13-18, 2014.

CÉSAR, M. R. A. Gênero, sexualidade e educação: notas para uma "epistemologia". Educar, Curitiba, n.35, p.37-51, 2009.

CHARLOT, B. Da relação com o saber. Porto Alegre: Artmed, 2000.

CHEVALLARD, Y. La TranspositionDidactique: Du Savoir Savant au Savoir Ensigné.

Grenoble, La pensée Sauvage, 1991.

CLÉMENT P. La Biologie et as didactique, dixans de recherche. ASTER.Thèmes, thèses, tendances. Paris, n. 29, 1998.

CLÉMENT, P. Didactic Transposition and KVP Model: Conceptions as Interactions between scientific knowledge, values and social practices. ESERA Summer School, IEC, Univ Minho, Braga (Portugal), p.9-18, 2006.

DAYRELL, J. A escola "faz" as juventudes? Reflexões em Torno da Socialização Juvenil.

Revista Educação e Sociedade, Campinas, v.28, n.100, p.1105-1128, 2007.

DE TILIO, R.; MARTINS, M.; MORELLI, A. Um Recorte da Visão Contemporânea da

Sexualidade na Adolescência. Revista de InvestigaciónenPsicología, Lima, v.16, n.2, 2014.

Disponível

em:<revistasinvestigacion.unmsm.edu.pe/index.php/psico/article/download/6555/5822>Acess o em: 05 set. 2017.

DINIS, N.; ASINELLI-LUZ, A. Educação sexual na perspectiva histórico-cultural.

Educar em Revista, n.30, Curitiba 2007.

FELIPE, J.; GUIZO, B. S. Entre batons, esmaltes e fantasias. In: MEYER, D.; SOARES, R. (org.). Corpo, gênero e sexualidade. Porto Alegre: Mediação. p. 31-40, 2004.

FOUCAULT, M. História da sexualidade: a vontade de saber. Trad: ALBUQUERQUE, $M$. T.; ALBUQUERQUE, J. A. G. 11. ed. Rio de Janeiro: Graal, 1988.

FOUCAULT, M. Sobre a história da sexualidade. In: Microfísica do poder. Rio de Janeiro, Brasil: Graal, p.243-276, 1995.

FURLANI, J. Encarar o desafio da Educação Sexual na escola. In: Secretaria de Estado da educação. Departamento de diversidade. Núcleo de gênero e diversidade sexual. Sexualidade. Curitiba: SEED-PR, p. 37-48, 2009.

GOMES, W. A.; COSTA, M.; SOBRINHO, C.; SANTOS, A.; BACELAR, E. Nível de informação sobre adolescência, puberdade e sexualidade entre adolescentes. Jornal de Pediatria, Rio de Janeiro, v.78, n.4, p.301-308, 2002.

GRIEP, R. H.; ARAÚJO, C. L. F.; BATISTA, S. M. Comportamento de risco para a infecção pelo HIV entre adolescentes atendidos em um centro de testagem e aconselhamento em DST/aids no Município do Rio de Janeiro, Brasil. Epidemiologia e Serviços de Saúde. v. 14, n. 2, p. 119- 126, 2005. 
HEILBORN, M. L.; SALEM, T.; ROHDEN, F.; BRANDãO, E.; KNAUTH, D.; VÍCTORA, C.; AQUINO, E.; MCCALLUM, C.; BOZON, M. Aproximações socioantropológicas sobre a gravidez na adolescência. Horizontes Antropológicos, Porto Alegre, v.8, n.17, p.13-45, 2002.

JEOLÁS, L. S.; FERRARI, R. A. P. Oficinas de prevenção em um serviço de saúde para adolescentes: espaço de reflexão e de conhecimento compartilhado. Ciência\&SaúdeColetiva, Rio de Janeiro, v.8, n.2, p.611-620, 2003.

JONES, R. K.; FENNELL, J.; HIGGINS, J. A.; BLANCHARD, K. Better than nothing or savvy risk-reduction practice? The importanceofwithdrawal. Contraception. n. 79, p. 407410, 2009.

LEAL, O. F. Sangue, fertilidade e práticas contraceptivas. In: Saúde e doença: um olhar antropológico. Rio de Janeiro, RJ, Brasil: Editora FIOCRUZ, 1994. Disponível em:<http://books.scielo.org/id/tdj4g/pdf/alves-9788575412763-11.pdf $>$. Acesso em: 20 set. 2017.

LELIS, R. T.; SOARES, G. B.; GARBIN, A. J. Í.; GARBIN, C. A. S. Discriminação vivenciada por pessoas que vivem com HIV/AIDS nos serviços de saúde: um estudo qualitativo. Revista Ciência Plural, n. 2, v. 3. p.17-29, 2016.

LOURO, G. L. Sexualidade: lições de casa. In: MEYER, D. E. E. (Org.). Saúde e sexualidade na escola. Porto Alegre, Brasil: Mediação Editora, 2000. p.85-96.

LOURO, G. L. Gênero, sexualidade e educação: uma perspectiva pós-estruturalista. Petrópolis, 16 ed., RJ: Editora Vozes, 2014.

MALISKA, I. C. A.; PADILHA, M. I.; VIEIRA, M.; BASTIANI, J. Percepções e significados do diagnóstico e convívio com o HIV/AIDS. Rev Gaúcha Enferm., Porto Alegre. n. 30, v. 1, 2009. p. 85-91.

MARANDINO, M.; BUENO, J.; GOMES, F. de O.; KRISTEL, F. L.; OLIVEIRA, A. Os usos da Teoria da Transposição Didática e da teoria Antropológica do Didático para o estudo da educação em museus de ciências. R. Labore Ens. Ci., Campo Grande, v.1, n.1, p. 69-97, 2016.

MENDOZA, M. A. G. La transposición didáctica: historia de un concepto. Revista Latinoamericana de Estudios Educativos. v. 1, 2005, p. 83-115, 2005. Disponível em: <http://www.redalyc.org/html/1341/134116845006/>. Acesso em: 09 set. 2017. NCHIA, L. N.; TAMESSE, J. L.; FONKENG, G. E.; CLÉMENT, P. Determinants of

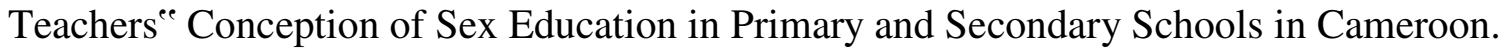

International Journal of Science and Research. v.4, n. 2, 2015.

NETTER, F. H. Atlas de anatomiahumana. Porto Alegre: Artmed, 2001.

NICOLAU, A.I. O.; MORAES, M. L. C. de.; LIMA, D. J. M.; AQUINO, P. de S.;

PINHEIRO, A. K. B. História reprodutiva de mulheres laqueadas. Actual Paul Enferm. v.23, n.5, p. 677-683, 2010.

OJEDA, B. S. A Tecedura das relações saber-poder em saúde: matizes de saberes e verdades. Tese (Doutorado em Psicologia) - Pontifícia universidade católica do Rio Grande do Sul. Faculdade de Psicologia. Porto Alegre, 2004.

OLIVEIRA, D.C., Análise de Conteúdo Temático Categorial: Uma proposta de sistematização. Rev. Enferm. UERJ, Rio de Janeiro, v.16, n.4, p. 569-76, 2008.

OLIVEIRA, M. L.; FARIA, J. C. N. d. M. Formação Inicial de Professores: desafios e possibilidades do ensino de reprodução e sexualidade no estágio curricular supervisionado.

Investigações em Ensino de Ciências, Porto Alegre, Brasil, v.16, n.3, p.509-528, 2011. ORLANDI, R.; TONELLI, M. J. F. Adolescência e paternidade: sobre os direitos de criar projetos e procriar. Psicologia em Estudo, v. 13, n. 2, p. 317-326, 2008.

PARKER, R., AGGLETTON, P. Estigma, discriminação e AIDS. Cidadania e Direitos, Rio de Janeiro, n. 1, 2001. Disponível 
em:<http://www.abiaids.org.br/_img/media/colecao\%20cidadania\%20direito.pdf $>$. Acesso em: 10 set. 2017.

REIS, T.; EGGERT, E. Ideologia de gênero: uma falácia construída sobre os planos de educação brasileiros. Educ. Soc., Campinas, v. 38, n. 138, p.9-26, 2017. Disponível em: $<$ http://www.scielo.br/pdf/es/v38n138/1678-4626-es-38-138-00009.pdf > . Acessoem: 15 set. 2017.

SABAH, S. S.; BOUJEMAA, A.; SALAH-EDDINE, K.; TAOUFIK, EL A.; DOMINIQUE, B. Sexuality education: Analysis of Moroccan teachers' and future teachers' conceptions. USChina EducationReview. v. 7, n .8, p. 28-36, 2010.

SANTOS, A.; CARVALHO, C. V. Gravidez na adolescência: um estudo exploratório.

Boletim de Psicologia, LVI, p. 135-151, 2006.

SILVA, R. C. P. da.; MEGID NETO, J. Formação de professores e educadores para abordagem da educação sexual na escola: o que mostram as pesquisas. Ciênc. educ. (Bauru), vol.12, n.2, p.185-197, 2006. Disponível em:<http://www.scielo.br/scielo.php?pid=S151673132006000200006\&script=sci_abstract\&tlng=pt. Acesso em: 22 set. 2017.

SIQUEIRA, M.; PIETROCOLA, M. A Transposição Didática aplicada a teoria contemporânea: A Física de Partículas elementares no Ensino Médio. In: X Encontro de Pesquisa em Ensino de Física - EPEF, 2006, Londrina. Anais. v. 1. p. 1-1. Disponível em: $<$ http://sites.usp.br/nupic/wp-

content/uploads/sites/293/2016/05/Maxwell_A_TRANSPOSICAO_DIDATICA_APLICADA .pdf>. Acesso em: 23 set, 2017.

SPOSITO, M. P. Juventude e Escolarização (1980-1998). Brasília: MEC/INEP/COMPED, 2002.UNAIDS BRASIL. Estatísticas. Disponível em: https://unaids.org.br/estatisticas/.

Acessoem: 01. Outubro/2017.

WINSLØW, C. Anthropological theory of didactic phenomena: some examples and principles of its use in the study of mathematics education. Un Panorama de TAD, Docume, p.117138. 2011.

WITTER, G.; GUIMARÃES, E. Percepções de adolescentes grávidas em relação a seus familiares e parceiros. Psicologia: ciência e profissão, Brasília, v.28, n.3, p.548-557, 2008.

ZEKERMAN, Z.; WEISS, D. B.; ORVIETO, R. Does preejaculatory penile secretion originating from Cowper's gland contain sperm? Journal of Assisted Reproduction and Genetics. n. 20, v. 4, p. 157-159, 2003.

\section{SOBRE OS AUTORES}

GISÉLI DUARTE BASTOS. Formada em Ciências Biológicas e Doutora em Educação em Ciências pelo Programa de Pós-Graduação Educação em Ciências: Química da Vida e Saúde (PPGECQVS) da Universidade Federal de Santa Maria (UFSM). Realizou o estudo em questão durante o doutoramento. Atualmente é Técnica em Assuntos Educacionais na UFSM, atuando no Centro de Educação.

ROSEMAR DE FÁTIMA VESTENA. Formada em Ciências Biológicas e Professora Doutora na Universidade Franciscana (UFN), atuando no Curso de Pedagogia e no Programa de Pós-Graduação em Ensino de Ciências e Matemática. Foi co-orientadora de doutorado da primeira autora do artigo.

LENIRA MARIA NUNES SEPEL. Formada em Ciências Biológicas e Professora Doutora na UFSM, atuando nos Cursos de Ciências Biológicas, Cursos da área da Saúde e no PPGECQVS. Foi orientadora de doutorado da primeira autora do artigo. 